\title{
The true cost of hidden waiting times for cataract surgery in Australia
}

\author{
Jessie Huang-Lunga,b,g, Blake Angell ${ }^{\mathrm{b}}$, Anna Palagyi ${ }^{\mathrm{b}}$, Hugh R Taylor ${ }^{\mathrm{c}}$, \\ Andrew White ${ }^{\mathrm{d}, \mathrm{e}, \mathrm{f}}$, Peter McCluskeye and Lisa Keay ${ }^{\mathrm{a}, \mathrm{b}}$
}

a School of Optometry and Vision Science, UNSW Sydney, Australia

b The George Institute for Global Health, UNSW Sydney, Australia

c Indigenous Eye Health Unit, Melbourne School of Population and Global Health, University of Melbourne, Victoria, Australia

a Department of Ophthalmology, Westmead Hospital, Western Sydney Local Health District, NSW, Australia

e Save Sight Institute, Faculty of Medicine and Health, University of Sydney, NSW, Australia

${ }^{f}$ Centre for Vision Research, Westmead Institute for Medical Research, Sydney, NSW, Australia

g Corresponding author: jessie.huang@unsw.edu.au

\section{Article history}

\section{Publication date: October 2021}

Citation: Huang-Lung J, Angell B, Palagyi A, Taylor HR, White A, McCluskey P, Keay L. The true cost of hidden waiting times for cataract surgery in Australia. Public Health Res Pract. 2021; Online early publication. https://doi.org/10.17061/phrp31342116

\section{Key points}

- Waiting times for public cataract surgery vary across Australian jurisdictions, ranging from 4 to 30 months

- Cataract causes vision impairment, negatively affecting a person's ability to work, care for others, drive and perform activities of daily living

- Investment in cataract services to reduce waiting times would likely result in health system cost savings for governments by preventing fall-related injuries

\section{Abstract}

Cataract surgery is a safe, effective and common elective procedure in Australia but access is inequitable. True waiting times for cataract care are undisclosed or inconsistently reported by governments. Estimates of true waiting times range from 4 to 30 months and have been extended during the coronavirus disease 2019 (COVID-19) pandemic. Comparative analysis revealed that reducing waiting periods from 12 to 3 months would result in estimated public health system cost savings of $\$ 6.6$ million by preventing 50679 falls. Investment in public cataract services to address current unmet needs would prevent avoidable vision impairment and associated negative consequences.

\section{Introduction}

Cataract is a leading cause of visual impairment in Australia, affecting $20 \%$ of Aboriginal and Torres Strait Islander (Indigenous) people (40 years and older) and $14 \%$ of non-Indigenous Australians (50 years and older). ${ }^{1}$ People with cataracts experience blurred vision, reduced contrast sensitivity and increased glare sensitivity, affecting their ability to work, care for others, drive and perform activities of daily living. Vision loss from cataracts disproportionately affects Indigenous Australians (adjusted odds ratio: 2.95) and people with lower educational attainment and socioeconomic status. ${ }^{2}$

Treatment with cataract surgery is safe, effective ${ }^{3}$ and cost-effective ${ }^{4}$, yet access to surgery in Australia is currently inequitable. ${ }^{5}$ Privately funded patients may have surgery within weeks of diagnosis but publicly funded patients typically face longer waiting periods. ${ }^{6}$ Because a higher proportion of Indigenous people undergoing cataract surgery access surgery as public patients $\left(80 \%{ }^{5}\right.$ compared with $29 \%$ of non-Indigenous Australians $\left.{ }^{7}\right)$, the impact of longer waiting times in public hospitals falls most heavily on them. 
Further disparities exist within public hospitals, with $36 \%$ longer median waiting times for Indigenous patients compared with other Australians. ${ }^{6}$ Lower cataract surgery coverage rates (proportion of people with cataract who have undergone surgery) in Indigenous people (61.5\% versus $88 \%$ for non-Indigenous Australians) also indicate an unmet need for cataract services. ${ }^{8}$

\section{The 'wait for the wait'}

Cataract surgery is one of the most common elective procedures performed in public hospitals. Waiting times for surgery are routinely reported by the Australian Institute of Health and Welfare. ${ }^{6}$ In 2018-19, New South Wales (NSW) had the longest waits (50th percentile time within which $50 \%$ of patients waitlisted for cataract surgery were admitted - 8 months; 90th percentile 11 months) and Victoria, the shortest (50th percentile 1 month; 90th percentile 4 months). ${ }^{6}$ However, these data reflect only part of the picture; they only represent time elapsed from addition to a public hospital waiting list to surgical admission. They do not capture time elapsed from initial diagnosis and referral by an optometrist or general medical practitioner to an ophthalmologist for confirmation of diagnosis, presurgical assessment, or subsequent addition to a surgical wait list.

The waiting times for initial referrals to public hospital outpatient ophthalmology services are often characterised as the 'hidden waiting list' or the 'wait for the wait'. In NSW, Western Australia, the Australian Capital Territory and the Northern Territory these are not publicly reported. ${ }^{9}$ However, a study examining 400 cataract referrals in two major metropolitan hospitals in NSW revealed that $61 \%$ of patients were still waiting for an initial outpatient appointment 12 months after being referred. ${ }^{10}$

Despite some inconsistency in collection and reporting methods, Victoria, South Australia (SA), Queensland and Tasmania do report some wait time statistics for hospital ophthalmology outpatient services. Before the coronavirus disease 2019 (COVID-19) pandemic, in 2019 the median wait time was 3 months in Victoria ${ }^{11}$ and 15 months on average in SA for routine, non-urgent ocular conditions including cataract. ${ }^{12}$ In Queensland, 90th percentile wait times could be 10 to 20 months depending on level of visual impairment at time of referral. ${ }^{13}$ Similarly, in Tasmania 75th percentile wait times for initial ophthalmology assessments were 6 to 12 months. ${ }^{14}$

Based on the waiting periods discussed above, in the best-case scenario a public patient would have cataract surgery within 4 months of referral, and in the worst case they would wait more than 30 months (2.5 years). In response to the COVID-19 pandemic, the Australian Government mandated all elective surgery be paused on 26 March 2020. During the ensuing months, surgeries were gradually resumed at different rates across the states and territories. These pauses in surgical admissions have created an additional backlog of surgeries and contributed to increased waiting times for patients. ${ }^{15}$

\section{Negative health consequences}

Delays in cataract surgery are associated with negative consequences for patients, including increased risk of injury because of falls ${ }^{16}$ and loss of driver licence or driving cessation (25\%). ${ }^{17}$ These can result in a loss of independence, social isolation and exacerbate depressive symptoms. ${ }^{18}$ Cataract surgery is a costeffective intervention ${ }^{4}$ and can significantly improve quality of life. ${ }^{3}$

We conducted a comparative analysis from a public health system perspective, during a 3-year period, to estimate government costs and outcomes associated with different waiting times for cataract surgery. Publicly funded health service costs were modelled, considering direct hospital costs for bilateral cataract surgery, preand post-operative assessments and indirect hospital costs associated with treating fall- and motor vehicle crash-related injuries.

Based on the National Eye Health Survey $2016^{2}$ and Australian population projections ${ }^{19,20}$, it was estimated that 243139 people were living with visually significant cataracts (visual acuity worse than 6/12) in 2020 (Supplementary Table S1, available from: doi. org/10.26190/8ESR-8H29). Of those, approximately $29 \%$ of non-Indigenous Australians ${ }^{7}$ and $80 \%$ of Indigenous Australians ${ }^{5}$ were likely to access bilateral cataract surgery as publicly funded patients, totalling 75924 people and 151848 surgeries.

\section{Health system costs}

The inflation-adjusted cost of cataract surgery and three ophthalmology consultations (one pre- and two postoperative) was estimated at $\$ 3713$ per eye in $2020 .{ }^{21}$ Assuming bilateral cataract surgery for 75924 patients and a 12-month waiting period for each eye, total health system costs were estimated at $\$ 550.3$ million over 3 years (Table 1). During this period, these cataract patients will likely suffer 199680 falls (Supplementary Table S4, available from: doi.org/10.26190/8ESR-8H29) and 2697 injurious motor vehicle crashes (Supplementary Table S5, available from: doi.org/10.26190/8ESR-8H29).

Reducing the waiting time for cataract surgery from 12 months to 3 months, resulted in a $\$ 13.4$ million increase in health system costs for surgery and perioperative consultations in 2019-20 dollars. By reducing waiting times to 3 months, we estimated that 50679 falls would be avoided (Table 1). Interestingly, there was a small increase in 141 motor vehicle crashes because of a higher crash rate after second eye surgery compared with the period after first eye surgery. ${ }^{25}$ Possible reasons for this include increasing age, and increased exposure 
Table 1. Comparison of number of falls, motor vehicle crashes and public health system costs associated with (A) 12 month and (B) 3 month waiting times for cataract surgery. Total costs in \$A millions (\$M) are shown over a 3-year period presented in 2019-20 dollars ${ }^{a}$

\begin{tabular}{|c|c|c|c|c|}
\hline Item description & $\begin{array}{l}\text { Public health system } \\
\text { cost }\end{array}$ & (A) 12-month wait & (B) 3-month wait & $\begin{array}{l}\text { Difference } \\
\text { (B-A) }\end{array}$ \\
\hline $\begin{array}{l}\text { Routine cataract surgery: AR-DRG: C16Z - lens } \\
\text { interventions, NHCDC }{ }^{21}\end{array}$ & $\$ 2967^{b}$ per surgery & 151848 surgeries & $\begin{array}{l}151848 \\
\text { surgeries }\end{array}$ & 0 surgeries \\
\hline $\begin{array}{l}\text { Non-admitted ophthalmology consultations: } \\
3 \text { per eye: } 1 \text { pre-operative and } 2 \text { postoperative } \\
\text { (Tier } 2 \text { class: } 20.17 \text { - ophthalmology, NHCDC20) }\end{array}$ & $\$ 248.5^{b}$ per consult & 455544 consults & 455544 consults & 0 consults \\
\hline Total cost of surgery and consultations & & $\$ 550.3 \mathrm{M}^{\mathrm{a}}$ & $\$ 563.7 \mathrm{M}$ & $\$ 13.4 \mathrm{M}$ \\
\hline \multicolumn{5}{|l|}{ Falls while waiting for cataract surgery } \\
\hline $\begin{array}{l}\text { Falls incidence rate (per person-year) })^{c} \\
\text { Before first surgery: } 1.17(95 \% \mathrm{Cl}: 0.93,1.46)^{21} \\
\text { Between surgeries: } 0.88(95 \% \mathrm{Cl}: 0.66,1.17)^{21} \\
\text { After second surgery: } 0.58(95 \% \mathrm{Cl}: 0.53,0.79)^{22}\end{array}$ & $\begin{array}{l}\text { \$409b }(95 \% \text { Cl: } \\
\text { \$173-642) per falld }\end{array}$ & 199680 falls & 149001 falls & -50679 falls \\
\hline \multicolumn{5}{|l|}{ Motor vehicle crashes before and after cataract surgery } \\
\hline $\begin{array}{l}\text { Crash rate (per person-year) } \\
\text { Before first surgery: } 0.0164 \\
\text { Between surgeries: } 0.0064 \\
\text { After second surgery: } 0.0127\end{array}$ & $\begin{array}{l}\$ 2076^{b} \text { per injurious } \\
\text { crash }^{f}\end{array}$ & 2697 crashes & 2838 crashes & 141 crashes \\
\hline Total Cost & & $\$ 634.3 \mathrm{M}$ & $\$ 627.7 \mathrm{M}$ & $-\$ 6.6 \mathrm{M}$ \\
\hline
\end{tabular}

AR-DRG = Australia Refined Diagnosis Related Groups; NHCDC = National Hospital Cost Data Collection

a A discount rate of $5 \%$ was applied in cost-effectiveness analysis to account for time preference, allowing adjustment of future costs to present value

b Costs in financial year 2019-20. Adjusted for inflation using the Reserve Bank of Australia Inflation Calculator, available from: www.rba.gov. au/calculator

Falls incidence rates reported by Palagyi et al22 are crude rates; Keay et al. ${ }^{23}$ reported an age and sex-adjusted rate. See Supplementary Table S4 for calculations of falls data, available from: doi.org/10.26190/8ESR-8H29

Average cost of a fall was based on the 'usual care' group in Hewitt et al. ${ }^{24}$

Crash rates were estimated from Meuleners et al. ${ }^{26}$ (Supplementary Table S2, available from: doi.org/10.26190/8ESR-8H29)

Cost per injurious crash were estimated from Australian Automobile Association Report ${ }^{25}$ (Supplementary Table S3, available from: doi. org/10.26190/8ESR-8H29)

to more risky driving situations after both eye surgeries. ${ }^{26}$ Nonetheless, our analysis revealed a significant reduction in falls and modest health system cost savings of an estimated \$6.6 million (Table 1).

\section{Conclusion}

Eliminating unnecessary delays to cataract surgery would therefore not only lead to better outcomes for patients but also alleviate an economic burden on the health system. Furthermore, the cost savings from this analysis do not account for longer-term costs to society and individuals from falls and motor vehicle crashes, including loss of life, disability care, loss of income, legal system costs, property damage and reduced quality of life. Hence, they are likely to be an underestimate of the potential benefits to society overall.

Greater investment in public cataract services will prevent future avoidable vision impairment and associated negative health consequences. Other strategies that could potentially improve access and efficiency include high-volume cataract surgery services to increase capacity and standardise referral and triage processes to ensure that referrals are appropriately targeted. Furthermore, policy changes to support culturally appropriate services, fast tracking of referrals, and prioritisation of surgery for Indigenous patients can reduce current inequities in access. Finally, adoption of a national standard for data collection of waiting times, and greater transparency in reporting, would enable better insight into the true waiting times for patients referred to public hospitals and allow tracking of future progress.

\section{Acknowledgements}

Grant support from Vision 2020 Australia was provided to authors: JHL, BA and LK for this work. Vision 2020 Australia is the national peak body for the eye health and vision sector and a part of a global initiative of the World Health Organisation and the International Agency for the Prevention of Blindness, 'VISION 2020: The Right to Sight'. 


\section{Peer review and provenance}

Externally peer reviewed, not commissioned.

\section{Competing interests}

None declared.

\section{Author contributions}

JHL was responsible for data acquisition, analysis and drafting the manuscript. BA was responsible for data analysis and AP was responsible for data interpretation, and both critically revised the manuscript. $\mathrm{HT}, \mathrm{AW}$ and PM were responsible for design of the work and criticially appraising the manuscript. LK was responsible for conception and critically revising the manuscript. All authors approved the final manuscript.

\section{References}

1. Foreman J, Keel S, Xie J, van Wijngaarden P, Crowston J, Taylor HR, et al. National Eye Health Survey. Australia: Centre for Eye Research Australia and Vision 2020; 2016 [cited 2020 Mar 23]. Available from: www. vision2020australia.org.au/wp-content/uploads/2019/06/ National-Eye-Health-Survey_Full-Report_FINAL.pdf

2. Keel S, McGuiness MB, Foreman J, Taylor HR, Dirani M. The prevalence of visually significant cataract in the Australian National Eye Health Survey. Eye (Lond). 2019;33(6):957-64.

3. Jayamanne DG, Allen ED, Wood CM, Currie S. Correlation between early, measurable improvement in quality of life and speed of visual rehabilitation after phacoemulsification. J Cataract Refract Surg. 1999;25(8):1135-9.

4. National Institute for Health and Care Excellence (UK). Cataracts in adults: management. London: NICE; 2017 [cited 2021 May 31]. Available from: www.nice. org.uk/guidance/ng77/resources/cataracts-in-adultsmanagement-pdf-1837639266757

5. Randall DA, Reinten T, Maher L, Lujic S, Stewart J, Keay $L$, et al. Disparities in cataract surgery between Aboriginal and non-Aboriginal people in New South Wales, Australia. Clin Exp Ophthalmol. 2014;42(7):629-36.

6. Australian Institute of Health and Welfare. Elective surgery waiting times 2018-19 data tables. Canberra: AlHW; 2020 [cited 2020 Mar 31]. Available from: www. aihw.gov.au/reports-data/myhospitals/content/datadownloads
7. Australian Commission on Safety and Quality in Health Care. Australian atlas of healthcare variation 2017: 4.6 cataract surgery hospitalisations 40 years and over. Sydney: ACSQHC; 2017 [cited 2020 Jun 18]. Available from: www.safetyandquality.gov.au/sites/default/files/ migrated/4.6-Cataract-surgery.pdf

8. Foreman J, Xie J, Keel S, van Wijngaarden P, Crowston J, Taylor HR, Dirani M. Cataract surgery coverage rates for Indigenous and non-Indigenous Australians: the National Eye Health Survey. Med J Aust. 2017;207(6):256-61.

9. Duckett S. Getting an initial specialists' appointment is the hidden waitlist. The Conversation; 2018 Jul 16 [cited 2020 Mar 23]. Available from: www.theconversation.com/ getting-an-initial-specialists-appointment-is-the-hiddenwaitlist-99507

10. Do VQ, McCluskey P, Palagyi A, Stapleton FJ, White A, Carnt N, Keay L. Are cataract surgery referrals to public hospitals in Australia poorly targeted? Clin Exp Ophthalmol. 2018;46(4):364-70.

11. Victoria Agency for Health Information. Specialist clinics: routine first appointments (ophthalmology). Melbourne: Victoria State Government Department of Health and Human Services; 2019 [cited 2020 May 14]. Available from: www.vahi.vic.gov.au/specialist-clinics/routine-firstappointments

12. South Australia Health. Specialist outpatient clinics waiting time report. Adelaide: Government of South Australia; 2019 [cited 2020 May 14]. Available from: www. sahealth.sa.gov.au/wps/wcm/connect/public+content/ sa+health+internet/about+us/our+performance/specialist +outpatient+waiting+time+report

13. Queensland Health. Quarterly information for specialist outpatient at 01 January 2020 (ophthalmology). Brisbane: Queensland Government; 2019 [cited 2020 May 15]. Available from authors.

14. Tasmanian Health Service. Estimated outpatient appointment waiting times: Southern Region (ophthalmology). Hobart: Tasmanian Government; 2020 Mar 6 [cited 2020 May 15]. Available from: www. outpatients.tas.gov.au/clinicians/wait_times

15. Australian Institute of Health and Welfare. Elective surgery waiting times 2019-20 data tables. Canberra: AlHW; 2021 [cited 2021 Sep 23]. Available from: www. aihw.gov.au/reports-data/myhospitals/content/datadownloads

16. Harwood RH, Foss AJ, Osborn F, Gregson RM, Zaman A, Masud T. Falls and health status in elderly women following first eye cataract surgery: a randomised controlled trial. Br J Ophthalmol. 2005;89(1):53-9.

17. Keay L, Palagyi A, Do V, White A, Lamoureux E, Ivers RQ, et al. Vision and driving status of older Australians with cataract: an investigation of public hospital waiting lists. Clin Exp Optom. 2016;99(5):449-55. 
18. Palagyi A, Rogers K, Meuleners L, McCluskey P, White $\mathrm{A}, \mathrm{Ng} \mathrm{JQ}$, et al. Depressive symptoms in older adults awaiting cataract surgery. Clin Exp Ophthalmol. 2016;44(9):789-96.

19. Australian Bureau of Statistics. Population projections, Australia, 2017 (base)-2066. Canberra: ABS; 2018 Nov 22 [cited 2020 Apr 1]. Available from: www. abs.gov.au/AUSSTATS/abs@.nsf/mf/3222.0

20. Australian Bureau of Statistics. Estimates and projections, Aboriginal and Torres Strait Islander Australians, 20062031. Canberra: ABS; 2019 Jul 11 [cited 2020 Apr 1]. Available from: www.abs.gov.au/statistics/people/ aboriginal-and-torres-strait-islander-peoples/estimatesand-projections-aboriginal-and-torres-strait-islanderaustralians/latest-release

21. Independent Hospital Pricing Authority (IHPA). National hospital cost data collection report: public sector, round 22 (financial year 2017-18). Canberra: IHPA; 2018 [cited 2020 Jun 14]. Available from: www.inpa.gov.au/ publications/national-hospital-cost-data-collection-datarequest-specifications-round-22
22. Palagyi A, Morlet N, McCluskey P, White A, Meuleners L, $\mathrm{Ng} \mathrm{JQ}$, et al. Visual and refractive associations with falls after first-eye cataract surgery. J Cataract Refract Surg. 2017;43(10):1313-21.

23. Keay L, Ho KC, Rogers K, McCluskey PJ, White AJ, Morlet N, et al. Reductions in the incidence of falls after first and second eye cataract surgery. Invest Ophthalmol Vis Sci. 2019;60(9):1389.

24. Hewitt J, Saing S, Goodall S, Henwood T, Clemson L, Refshauge K. An economic evaluation of the SUNBEAM programme: a falls-prevention randomized controlled trial in residential aged care. Clin Rehabil. 2019;33(3):524-34.

25. Potterton P, Ockwell A, Cross J. Cost of road trauma in Australia 2015. Economic Connections report for the Australian Automobile Association. Canberra: AAA; 2017 [cited 2020 May 20]. Available from: www.aaa.asn.au/ wp-content/uploads/2018/03/AAA-ECON_Cost-of-roadtrauma-full-report_Sep-2017.pdf

26. Meuleners LB, Brameld K, Fraser ML, Chow K. The impact of first- and second-eye cataract surgery on motor vehicle crashes and associated costs. Age Ageing. 2018;48(1):128-33.

\section{Copyright: (c) (i) (5)}

(C) 2021 Huang-Lung et al. This article is licensed under the Creative Commons Attribution-NonCommercial-ShareAlike 4.0 International Licence, which allows others to redistribute, adapt and share this work non-commercially provided they attribute the work and any adapted version of it is distributed under the same Creative Commons licence terms. See: www.creativecommons.org/licenses/by-nc-sa/4.0/ 